\title{
Decadal climate variability and the global \\ energy balance
}

doi: $10.22498 /$ pages.25.1.20

\section{Richard P. Allan}

\author{
Department of Meteorology, University of Reading, UK
}

\section{Introduction}

The Earth's energy balance represents a nexus between radiative forcings which set the trajectory of climate change and feedbacks which determine the nature and magnitude of the response. Yet entwined within the observed decadal variability and trends are complex, unforced interactions within the climate system. The energy and water cycles are intimately linked and observed precipitation changes contain signals from unforced fluctuations as well as rapid adjustments to radiative forcing and responses to the longer-term heating or cooling; this is mediated by the oceans which dominate the effective heat capacity of the climate system. It is essential to monitor key indicators of climate including the evolving energy budget to interpret global change in the context of intrinsic multidecadal variability.

Fig. 1 displays variability and change in global-mean surface temperature, atmospheric moisture, precipitation and the top of atmosphere energy balance over the period 1979-2016. This includes a mixture of observationallybased estimates combined with the European Centre for Medium-range Weather Forecasts (ECMWF) interim reanalysis (ERAI) (Dee et al., 2011), which continually adjusts a numerical model by applying data assimilation to an evolving and diverse set of global observations. Also shown are atmosphere-only "AMIP" experiments from phase 5 of the Coupled Model Intercomparison Project (CMIP5) (Taylor et al., 2011) which apply realistic radiative forcing and observed surface temperature and sea ice distributions over the 1979-2008 period (an ensemble mean with a one standard deviation spread across models are displayed). The surface temperature, water vapor and precipitation variability depicted in Fig. 1a-c update Allan et al. (2014a) while Fig. 1d exploits top of atmosphere energy budget estimates from Allan et al. (2014b).

Considering deseasonalised monthly surface temperature (Ts) anomalies from HadCRUTv4.5 (Morice et al., 2012), the globe has warmed at $0.16 \mathrm{~K} /$ decade when considering the period 1988-2015 chosen to coincide with the introduction of the special sensor microwave imager (SSM/I) series of satellite instruments in 1987.
This trend is punctuated by episodic warm El Niño events (e.g. 1997/98, 2015/16) and cool La Niña episodes (e.g 1999,2011 ) which alter global monthly mean surface temperature by up to around 0.2-0.3 K. At longer timescale, increased La Niña frequency linked to multi-decadal strengthening of the Walker circulation (L'Heureux et al., 2013) suppressed decadal surface warming rates during 2000-2010 (Xie \& Kosaka, 2017). The opposite was observed during 1980-1990 characterized by recurrent and strong El Nino events, which boosted the warming trend. The Ts anomalies are well represented by AMIP

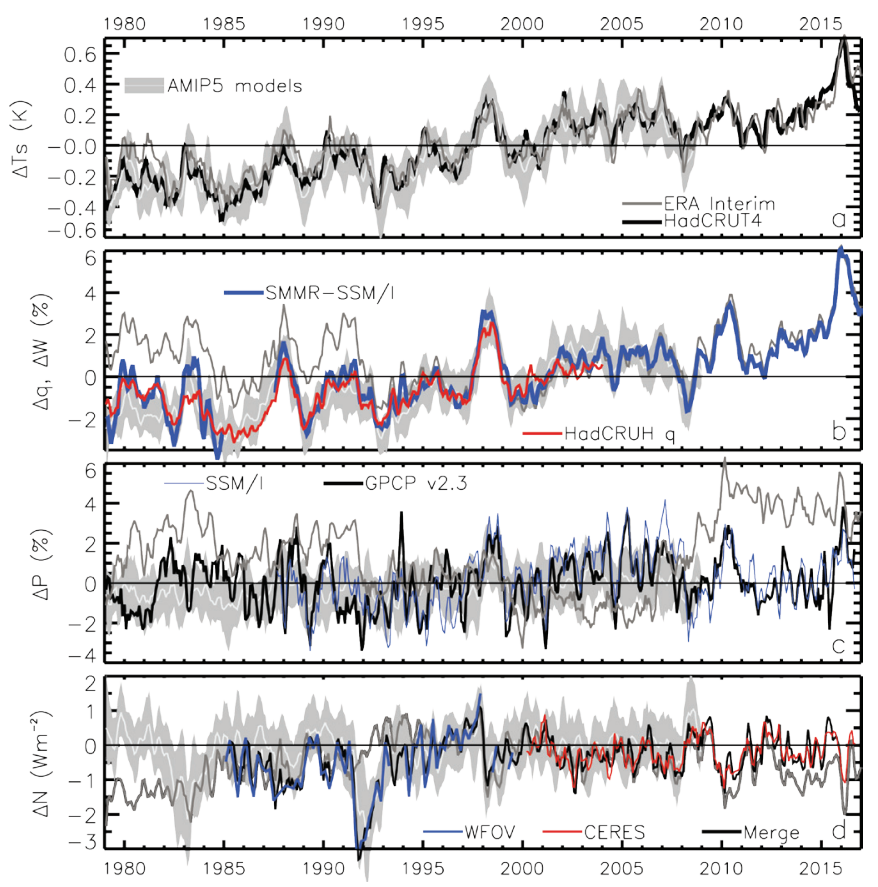

Figure 1: Deseasonalised monthly anomalies with respect to $1995-2000$ in global mean (a) surface temperature, (b) column integrated or surface water vapor, (c) precipitation and (d) top of atmosphere net radiation for a combination of satellite and surface observationally-based estimates, atmosphere-only climate models using prescribed observed sea surface temperature and sea ice (AMIP) and a the ERAI reanalysis over the period 1979-2016 (3 month smoothing is applied). 
simulations (which prescribe observed sea surface temperatures while land Ts is explicitly simulated) and ERAI (which also prescribes ocean surface temperature but land Ts is somewhat constrained by observations through data assimilation). ERAI anomalies up to $0.2 \mathrm{~K}$ higher than HadCRUT4 in late 2016 are likely due in part to the lack of interpolation of observed values over the Arctic (Cowtan and Way, 2014).

Atmospheric column integrated water vapour closely tracks the temperature changes, as expected from the strong temperature dependence of saturation vapor pressure determined by the Clausius Clapeyron equation, and there is broad agreement between the range of surface in situ observations, satellite-based datasets and AMIP simulations. The satellite estimates sample the icefree ocean (a combination of microwave measurements taken from the F08/F11/F13/F17 series of Defence Meteorological Satellite Program satellites; Wentz, 2013) and are here combined with ERAI over remaining regions: these indicate a moistening of $1.2 \% /$ decade for 1988-2015; interestingly this trend is only marginally suppressed (by about $-0.2 \%$ /decade) during the 2000 2012 period of slower surface warming.

The resultant additional water vapor continuum absorption in the more transparent window regions of the infrared spectrum cause a reduction in surface loss of clear-sky longwave radiation of $\sim 1.4 \mathrm{Wm}^{-2}$ per $\mathrm{mm}$ of precipitable water vapor (Allan, 2009) which translates to reduced clear-sky surface net longwave radiative loss of $\sim 0.4 \mathrm{Wm}^{-2}$ per decade, consistent with more detailed modelling estimates (Wild et al., 2008). Enhanced absorption of sunlight by the increasing water vapor additionally reduces net radiative energy loss by the atmosphere and contributes to solar "dimming" at the surface (Haywood et al., 2011).

Observed global mean column integrated moisture increases with $\mathrm{Ts}$ at $7.2 \pm 0.4 \% / \mathrm{K}$ based on linear regression $(r=0.87)$, in agreement with the combination of Ts and moisture trends. This is consistent with simple thermodynamics which strongly determine global low altitude water vapor although variability and change over land appears less constrained (Simmons et al. 2010). Climate model AMIP simulations capture the SSM/Ibased variability and earlier Scanning Multi-channel Microwave Radiometer (SMMR)-based microwave estimates while ERAI anomalies are in close agreement after the 1991-1993 period during which an unrealistic drop in global ocean moisture affects the reanalysis. There is a remarkable agreement in interannual variability between independent HadCRUH surface specific humidity observations (Willett et al., 2008) and the satellite-based estimates of column integrated moisture, with a consistent increasing trend over the coinciding 1988-2004 period (Allan et al., 2014a).
Low altitude moisture provides the fuel for rainfall events (Trenberth et al., 2003) yet global precipitation is determined by atmospheric energy balance, primarily attributable to net radiative energy loss (Allen and Ingram, 2002; O'Gorman et al., 2012). Given these global driving factors, combined with the heterogeneous distribution of precipitation and associated measurement limitations, it is no surprise that variability and trends in global precipitation (Fig. 1c) contrast markedly to that of water vapor and temperature (Fig. 1a-b). Global mean precipitation from the Global Precipitation Climatology Project (GPCP v2.3; Adler et al., 2017), a combination of satellite-based and land surface gauge-based estimates, appears to display greater month to month variability compared to longer time-scale changes than temperature or water vapor; co-variability with these variables and similarity to AMIP5 simulations appears less coherent (Fig. 1c) with barely significant global precipitation trends during 1988-2015 (0.3\%/decade; $r=0.19)$ and no significant trend during the period of slower surface warming 2000-2012, consistent with understanding of radiative forcing and precipitation response (Allan et al., 2014a; Saltzmann, 2016). It is reassuring but no surprise that SSM/I-based estimates agree with GPCP since SSM/I data over the ice-free ocean is used in the generation of GPCP estimates while over other regions data is identical in this merged estimate. However, the changing observing system seriously compromises the global precipitation variability depicted by ERAI as previously reported (Dee et al., 2011; Allan et al., 2014a). Interannual coupling of GPCP precipitation with HadCRUT Ts over this period is $3.0 \pm 0.7 \% / K(r=0.37)$, consistent with estimates of temperature dependent precipitation sensitivity (Andrews et al., 2010; Myhre et al., 2017). Global precipitation increases with global Ts primarily due to the enhanced radiative loss for higher surface and atmospheric temperatures, set by the thermodynamics of the coupled system (Roderick et al. 2014; Myhre et al., 2017) although this is tempered by the additional absorption of sunlight by higher water vapor loadings (Allan 2009) and modified by sensible heat flux changes. However, apparent short-term increases of 2-3\% in global precipitation during warm El Niño events (e.g. 2010 and 2016) coincide with increases in Ts of just $0.2-0.3 \mathrm{~K}$, a much greater precipitation sensitivity than anticipated from energy budget considerations and indicative of a subtler influence of spatial reorganisation of circulation systems and energy in the climate system.

Variability in net downward top of atmosphere radiation imbalance by satellites are generally well captured by the AMIP5 simulations (Allan et al., 2014b) indicating that radiative forcing and feedback response are well simulated when realistic ocean surface temperature is prescribed. ERAI also captures month to month variability in the radiation budget remarkably well given that cloud cover, which dominates these fluctuations, is not directly assimilated. However, decadal variability 
and trends are unrealistic and the reanalysis does not represent volcanic radiative forcing as evident from the lack of response to the 1991 Pinatubo eruption. Variability is dominated by cooling following the Pinatubo volcanic eruption in 1991 (up to $-3 \mathrm{Wm}^{-2}$ caused by the reflective volcanic aerosol haze in the stratosphere) and El Niño events in which a warmer atmosphere loses more energy to space through infrared emission. This reduced energy uptake is of order $1 \mathrm{Wm}^{-2}$ although an increase in energy uptake of about $0.2 \mathrm{Wm}^{-2}$ can occur as El Niño builds (Johnson and Birnbaum, 2017) and substantial reorganisation of energy in the upper $400 \mathrm{~m}$ of the ocean occurs (Roemmich et al., 2015). Recent estimates of net radiative imbalance at the top of the atmosphere of 0.6-0.8 Wm-2 for 2005-2015 (Johnson et al., 2016) are primarily determined by ocean heat content changes measured by Argo buoys; this and additional observations and assumptions are applied in anchoring the satellite records (Loeb et al., 2012) which themselves provide excellent representation of interannual variability and decadal trends. The net imbalance is remarkably stable over time with trends of just $0.02 \pm 0.01 \mathrm{Wm}^{-2}$ per decade over the period 1988-2015, substantially smaller than the expected uncertainty. This stability indicates no hiatus in anthropogenic radiative forcing despite slower global surface warming at the beginning of the 21 st century (Xie \& Kosaka, 2017) although there is intriguing evidence of distinct global energy budget response to Ts that influences interannual fluctuations, internal decadal variability and long-term climate response (Brown et al., 2014; Xie et al., 2015).

Ongoing monitoring of Earth's energy budget and other key climate indicators combining a range of observations, reanalyses and model simulations is valuable for (i) detecting unrealistic behaviour in observing systems, (ii) identifying unusual or significant climate fluctuations and trends and (iii) improving understanding of physical processes and feedbacks. Isolating internally generated interannual to decadal variability from longer term climate responses is essential for interpreting changes in the global water cycle (Gu et al., 2016; Sukhatme and Venugopal, 2017) and the fundamental driving factors involving Earth's energy balance (Palmer and McNeall, 2014; Trenbeth et al., 2016). This variability can potentially be exploited in elucidating regional feedbacks on internal decadal variability (Brown et al., 2014; Zhou et al., 2016; Xie et al., 2015) as well as in advancing understanding of how the spatial nature of climate change influences how sensitive the global climate is to radiative forcings (Gregory and Andrews, 2016). The regional manifestation of changes in the energy budget and water cycle have been identified globally (Myhre et al., 2017; Bony et al., 2013) and at hemispheric (Hwang et al., 2013; Loeb et al., 2016; Stephens et al., 2017) to continental scales (Bollasina et al., 2011; Dong and Sutton, 2015). Applying a regional energy budget perspective is informative in understanding these water cycle responses
(Muller and O'Gorman, 2011) and for tracking energy within the climate system: combining satellite radiation budget measurements with reanalysis energy transports to estimate surface fluxes can be used to identify regional decadal patterns of ocean heating (Liu et al., 2017) and potentially constrain ocean energy transports (Trenberth and Fasullo, 2017) and their changes from one decade to the next. These advances take observing systems and climate models to their limits (Desbruyères et al., 2016; Palmer, 2017; Wild, 2017). To further constrain long-term regional climate change responses to radiative forcings it is necessary to disentangle the distinct energy budget responses and feedbacks influencing internal decadal variability of the climate system.

\section{Acknowledgements}

Support was provided from the UK National Centre for Earth Observation (NCEO) and National Centre for Atmospheric Science (NCAS) and the Natural Environment Research Council SMURPHS (NE/ N006054/1) and DEEP-C (NE/K005480/1) projects. The World Climate Research Programme's Working Group on Coupled Modelling is acknowledged for developing the CMIP model archive, and we thank the climate modelling groups for producing and making available their model outputs; for CMIP, the U.S. Department of Energy's PCMDI provided coordinating support and led development of software infrastructure in partnership with the Global Organization for Earth System Science Portals. AMIP5 climate model data sets were extracted from the British Atmospheric Data Centre (http://badc.nerc.ac.uk/ home) and the Program for Climate Model Diagnosis and Intercomparison (pcmdi3.llnl.gov/esgcet). GPCP v2.3 data were extracted from http://gpcp.umd.edu. Merged radiation budget data (v3) are available from http:// www.met.reading.ac.uk/ sgs02rpa/research/DEEP-C/ GRL/ and CERES EBAF v2.8 and ERBS wide field of view (WFOV) v3 data was provided by the NASA Langley research centre. SSM/I and SSMIS v7 products were also obtained online (ftp.ssmi.com). HadCRUT4 data is available from http://www.metoffice.gov.uk/hadobs/ hadcrut4/.

\section{References}

Adler et al. (2017) An Update (Version 2.3) of the GPCP Monthly Analysis (in preparation).

Allan, R. P., C. Liu, M. Zahn, D. A. Lavers, E. Koukouvagias and A. Bodas-Salcedo (2014a) Physically consistent responses of the global atmospheric hydrological cycle in models and observations, Surv. Geophys., 35, 533-552, doi:10.1007/s10712-012-9213-z.

Allan, R. P., C. Liu, N. G. Loeb, M. D. Palmer, M. Roberts, D. Smith and P.-L. Vidale (2014b) Changes in global net radiative imbalance 1985-2012, Geophysical Research Letters, 41, 5588-559710.1002/2014GL060962 
Allen, M. R., and W. J. Ingram (2002), Constraints on future changes in climate and the hydrological cycle, Nature, 419, 224-232, doi:10.1038/nature01092.

Andrews, T., P. M. Forster, O. Boucher, N. Bellouin, and A. Jones (2010), Precipitation, radiative forcing and global temperature change, Geophys. Res. Lett., 37, L14701, doi:10.1029/2010GL043991.

Bollasina, Massimo, Yi Ming, and V Ramaswamy (2011) Anthropogenic aerosols and the weakening of the South Asian summer monsoon. Science, 334, 502-505 doi:10.1126/science.1204994.

Bony, S., G. Bellon, D. Klocke, S. Sherwood, S. Fermepinand S. Denvil (2013) Robust direct effect of carbon dioxide on tropical circulation and regional precipitation, Nature Geoscience 6, 447-451, doi:10.1038/ngeo1799

Brown, P. T., W. Li, L. Li, and Y. Ming (2014), Top-ofatmosphere radiative contribution to unforced decadal global temperature variability in climate models, Geophys. Res. Lett., 41, 5175-5183, doi:10.1002/2014GL060625.

Cowtan, K. and Way, R. G. (2014), Coverage bias in the HadCRUT4 temperature series and its impact on recent temperature trends. Q.J.R. Meteorol. Soc., 140: 19351944. doi:10.1002/qj.2297

Dee, D. P., Uppala, S. M., Simmons, A. J., Berrisford, P., Poli, P., Kobayashi, S., Andrae, U., Balmaseda, M. A., Balsamo, G., Bauer, P., Bechtold, P., Beljaars, A. C. M., van de Berg, L., Bidlot, J., Bormann, N., Delsol, C., Dragani, R., Fuentes, M., Geer, A. J., Haimberger, L., Healy, S. B., Hersbach, H., Hólm, E. V., Isaksen, L., Kållberg, P., Köhler, M., Matricardi, M., McNally, A. P., Monge-Sanz, B. M., Morcrette, J.-J., Park, B.-K., Peubey, C., de Rosnay, P., Tavolato, C., Thépaut, J.N. and Vitart, F. (2011), The ERA-Interim reanalysis: configuration and performance of the data assimilation system. Q.J.R. Meteorol. Soc., 137: 553-597. doi:10.1002/ qj.828

Desbruyères, D., McDonagh, E.L. \& King, B.A. (2016) Observational Advances in Estimates of Oceanic Heating, Curr Clim Change Rep, 2, 127-134, doi:10.1007/s40641016-0037-7

Dong, B. and R. Sutton (2015) Dominant role of greenhouse-gas forcing in the recovery of Sahel rainfall, Nature Clim. Ch., doi: 10.1038/nclimate2664

Gregory, J. M., and T. Andrews (2016), Variation in climate sensitivity and feedback parameters during the historical period, Geophys. Res. Lett., 43, 3911-3920, doi:10.1002/2016GL068406.

Gu, G., Adler, R.F. \& Huffman, G.J. Clim Dyn (2016) 46: 1091. doi:10.1007/s00382-015-2634-x
Haywood, J. M., N. Bellouin, A. Jones, O. Boucher, M. Wild, and K. P. Shine (2011), The roles of aerosol, water vapor and cloud in future global dimming/brightening, J. Geophys. Res., 116, D20203, doi:10.1029/2011JD016000. Hwang, Y-T., Frierson, D. M. W. \& Kang, S. M. Anthropogenic sulfate aerosol and the southward shift of tropical precipitation in the 20th century. Geophys. Res. Lett. 40, 1-6 (2013).

Johnson, G. C., and A. N. Birnbaum (2017), As El Niño builds, Pacific Warm Pool expands, ocean gains more heat, Geophys. Res. Lett., 44, 438-445, doi:10.1002/2016GL071767.

L'Heureux, M.L., S. Lee \& B. Lyon (2013), Recent multidecadal strengthening of the Walker circulation across the tropical Pacific, Nature Clim. Ch., 3, 571-576, doi:10.1038/nclimate 1840

Liu, C. Allan, R.P., M. Mayer, P. Hyder, N.G. Loeb , C.D. Roberts, M. Valdivieso, J. Edwards, P.-L. Vidale (2017) Evaluation of satellite and reanalysis-based global net surface energy flux and uncertainty estimates, J. Geophysical Research, doi: 10.1002/2017JD026616

Loeb, N. G., J. M. Lyman, G. C. Johnson, R. P. Allan, D. R. Doelling, T. Wong, B. J. Soden and G. L. Stephens (2012), Observed changes in top-of-the-atmosphere radiation and upper-ocean heating consistent within uncertainty, Nature Geoscience, 5, 110-113, doi:10.1038/ngeo1375

Loeb, N.G., H. Wang, A. Cheng, S. Kato, J.T. Fasullo, K.M. Xu and R.P. Allan (2016) Observational Constraints on Atmospheric and Oceanic Cross-Equatorial Heat Transports: Revisiting the Precipitation Asymmetry Problem in Climate Models, Climate Dynamics, 46, 32393257, 10.1007/s00382-015-2766-z.

Morice, C. P., J. J. Kennedy, N. A. Rayner, and P. D. Jones (2012), Quantifying uncertainties in global and regional temperature change using an ensemble of observational estimates: The HadCRUT4 dataset, J. Geophys. Res., 117, D08101, doi:10.1029/2011JD017187.

Muller CJ, O'Gorman PA (2011) An energetic perspective on the regional response of precipitation to climate change. Nat Clim Change 1:266-271

Myhre, G., P. Forster, B. Samset, Ø. Hodnebrog, J. Sillmann, S. Aalbergsjø, T. Andrews, 0. Boucher, G. Faluvegi, D. Flaeschner, T. Iversen, M. Kasoar, S. Kharin, A. Kirkevåg, J. Lamarque, D. Olivié, T. Richardson, D. Shindell, K. Shine, C. Stjern, T. Takemura, A. Voulgarakis, and F. Zwiers, 2017: PDRMIP: A Precipitation Driver and Response Model Intercomparison Project, Protocol and preliminary results. Bull. Amer. Meteor. Soc. doi:10.1175/ BAMS-D-16-0019.1, in press. 
O'Gorman, P. A., R. P. Allan, M. P. Byrne and M. Previdi (2012) Energetic constraints on precipitation under climate change, Surv. Geophys., 33, 585-608, doi: 10.1007/s10712-011-9159-6

Palmer, M. D., and D. J. McNeall (2014), Internal variability of Earth's energy budget simulated by CMIP5 climate models, Environ. Res. Lett., 9, 034016, doi:10.1088/17489326/9/3/034016.

Palmer, M.D. (2017) Reconciling Estimates of Ocean Heating and Earth's Radiation Budget, Curr Clim Change Rep, doi:10.1007/s40641-016-0053-7

Roderick, M. L., F. Sun, W. H. Lim, and G. D. Farquhar (2014), A general framework for understanding the response of the water cycle to global warming over land and ocean, Hydrol. Earth Syst. Sci., 18(5), 1575-1589, doi:10.5194/hess-18-1575-2014

Roemmich, D., J. Church, J. Gilson, D. Monselesan, P . Sutton and S. Wijffels (2015) Nature Clim. Change, 5, 240-245, doi:10.1038/nclimate2513.

Salzmann, M. (2016) Global warming without global mean precipitation increase? Science Advances, 2, doi:10.1126/sciadv.1501572

Simmons, A. J., K. M. Willett, P. D. Jones, P. W. Thorne, and D. P. Dee (2010), Low-frequency variations in surface atmospheric humidity, temperature, and precipitation: Inferences from reanalyses and monthly gridded observational data sets, J. Geophys. Res., 115, D01110, doi:10.1029/2009JD012442.

Stephens, G.L., Hakuba, M.Z., Hawcroft, M. J. M. Haywood, A. Behrangi, J. E. Kay, P. J Webster (2016) The Curious Nature of the Hemispheric Symmetry of the Earth's Water and Energy Balances, Curr Clim Change Rep, 2, 135-147, doi:10.1007/s40641-016-0043-9

Sukhatme, J. and Venugopal, V. (2017), Waxing and waning of observed extreme annual tropical rainfall. Q.J.R. Meteorol. Soc., 142: 102-107. doi:10.1002/qj.2633 Taylor KE, Stouffer RJ, Meehl GA (2011) An overview of CMIP5 and the experiment design. Bull Am Meteorol Soc 93:485-498. doi:10.1175/BAMS-D-11-00094.1

Trenberth KE, Dai A, Rasmussen RM, Parsons DB (2003) The changing character of precipitation. Bull Am Meteorol Soc 84:1205-1217

Trenberth, K., J. Fasullo, K. von Schuckmann, and L. Cheng (2016) Insights into Earth's Energy Imbalance from Multiple Sources. J. Climate, 29, 7495-7505, doi: 10.1175/JCLI-D-16-0339.1.
Wentz, F. J., (2013), SSM/I Version-7 Calibration Report, report number 011012, Remote Sensing Systems, Santa Rosa, CA, 46pp.

Wild, M. (2017) Towards Global Estimates of the Surface Energy Budget, Curr Clim Change Rep, doi:10.1007/ s40641-017-0058-x

Wild, M., J. Grieser, and C. Schär, 2008: Combined surface solar brightening and increasing greenhouse effect favour recent intensification of the hydrological cycle. Geophys. Res. Lett., doi:10.1029/2008GL034842

Willett, K.W., P.D. Jones, N.P. Gillett and P. W. Thorne, 2008: Recent changes in surface humidity: development of the HadCRUH dataset. J. Clim..21, 5364:5383

Xie, S.-P., Y. Kosaka, Y. M. Okumura (2016) Distinct energy budgets for anthropogenic and natural changes during global warming hiatus, Nature Geoscience 9, 29-33 (2016) doi:10.1038/ngeo2581, L17706.

Xie, SP. \& Kosaka, Y. (2017) What Caused the Global Surface Warming Hiatus of 1998-2013? Curr Clim Change Rep, 3, 128, doi:10.1007/s40641-017-0063-0

Zhou, C., M. D. Zelinka and S. A. Klein (2016), Impact of decadal cloud variations on the Earth's energy budget, Nature Geosci., 9, 871-874, doi:10.1038/NGE02828 